Shamima Akter Smriti', Shah Alimuzzaman Belal'1, Md. Mahbubul Haque², Md. Ismail Hossain³,

Nawshin Farzana², Abu Naser Md Ahsanul Haque2,4

1 Bangladesh University of Textiles, Dhaka 1208, Bangladesh

2 Daffodil International University, Dhaka 1207, Bangladesh

${ }^{3}$ Khulna University of Engineering and Technology, Khulna, Bangladesh

${ }^{4}$ Deakin University, Institute for Frontier Materials, Geelong, Victoria, 3216, Australia

\title{
Prognosis of Dimensional Stability and Mass per Unit Area of Single Jersey Cotton Knitted Fabric with Fuzzy Inference System
}

Napoved dimenzijske stabilnosti in ploščinske mase

bombažnega levo-desnega pletiva s sistemom mehkega sklepanja

\author{
Original Scientific Article/lzvirni znanstveni članek
}

Received/Prispelo 3-2019 • Accepted/Sprejeto 7-2019

\begin{abstract}
Endeavour has been made in this research work using experimental data for constructing a fuzzy inference model based on the Mamdani approach to prognosticate the shrinkage and mass per unit area of a single jersey cotton knitted fabric. To control the dimensional stability of the cotton knitted fabric in advance, an artificial intelligent system is required in the knitting industry which simulates all product and process variables and is able to give human-like decisions in advance. The most important controlling parameters of knitted fabric properties such as stitch length, yarn count and overfeed percentage in stenter were considered as input variables, and mass per unit area, lengthwise shrinkage and widthwise shrinkage as output variables. Overall, 35 experiments were conducted to construct the model, varying different parameters. The applicability of the model was validated by comparing the results from 15 newly conducted experiments. The coefficient of determination of predicted and actual data for mass per unit area, lengthwise shrinkage and widthwise shrinkage were $0.97,0.99$ and 0.99 , respectively which validates the model relatively effectively for an industrial application. The proposed model can assist a fabric manufacturer by taking a decision in selecting knitting and finishing parameters prior to producing the fabric. Moreover, it can reduce the time and energy required, and waste produced in the process by skipping the sample development step before bulk production.

Keywords: stenter machine, overfeed, fuzzy prediction, membership function
\end{abstract}

\section{Izvleček}

Za napovedovanje krčenja in ploščinske mase bombažnega levo-desnega pletiva so si z uporabo eksperimentalnih podatkov v tej raziskavi prizadevali izdelati model mehkega sklepanja, ki temelji na pristopu Mamdanija. Za nadzor dimenzijske stabilnosti bombažnega pletiva je v pletilnicah potreben umetni inteligentni sistem, ki simulira vse spremenljivke izdelka in procesa ter je sposoben oblikovati človeku podobne odločitve. Najpomembnejše lastnosti pletiva, ki jih je potrebno nadzirati, so dolžina zanke, dolžinska masa preje in odstotek prehitevanja pletiva na razpenjalnem sušilniku. Te so bile upoštevane kot vhodne spremenljivke, medtem ko so bile ploščinska masa, krčenje po dolžini in širini izhodne spremenljivke. Za izdelavo modela je bilo izvedenih skupno 35 eksperimentov z 
variiranjem parametrov. Uporabnost modela je bila potrjena s primerjavo z rezultati iz 15-ih na novo izvedenih eksperimentov. Koeficienti določenih predvidenih in dejanskih vrednosti ploščinske mase, krčenja po dolžini in širini so znašali 0,97, 0,99 in 0,99, kar potrjuje relativno učinkovitost modela za industrijsko uporabo. Predlagani model lahko pomaga proizvajalcu pletiv z odločitvijo o izbiri parametrov pletenja in dodelave pletiva. Poleg tega lahko zmanjša čas, energijo in odpadek, ki nastane v proizvodnji, s tem ko ni potrebno izdelati vzorca pred začetkom masovne proizvodnje.

Ključne besede: razpenjalni sušilnik, prehitevanje, mehko predvidevanje, funkcija članstva

\section{Introduction}

Knitted fabrics are generally a combination of a series of knitted loops which are readily perverted during its manufacturing process. Cotton knitted fabrics are very popular among customers, due to the excellence attributes of comfort; however, nowadays, the demand of customers has changed as they pay more attention to quality along with reasonable cost. A common complain from the customer's and manufacturer's side is the dimensional instability of cotton knitted fabrics [1]. During the knitting action, the casting off a new loop through the old loop by a needle develops some tension in yarn that initiates distortion in the loop shape. It has been reported that the stitch density of a single jersey fabric is controlled by loop length rather than yarn and knitting variables [2]. According to Munden, yarn properties would not dominante the knitted loop and after the removal of mechanical strains, the knitted loop would take a natural shape [3]. Again, the takedown mechanism and fabric spreader in the knitting machine produce both length- and widthwise tension in the fabric that also perverts the knitted loop shape. The latter will remain distorted after the removal from the machine. This type of loop distortion has a slight influence on the shrinkage properties of the finished fabric. This means that the loop distortion could be lessened by applying an appropriate finishing process in the knitted fabric [4].

The research of dimensional behaviour of weft knit ramie, cotton and viscose fabrics conducted by Li et al. [5] reveals that the loosely knitted fabrics of hydrophilic fibres, including cotton and viscose, undergo progressive shrinkage in the vertical (wale) dimension and progressive stretch in the horizontal (course) dimension. Moreover, it has been reported in a few studies that though the types of yarn like ring or compact yarn do not have a significant effect on shrinkage, the presence of elastomeric yarn and/ or tightness factor, yarn count and stitch length can have a great influence on dimensional properties [6-8]. Moreover, a few other factors such as the finishing process, washing, drying and relaxation state are also found crucial for the dimensional stability of knitted fabrics [9-11].

However, every change in the manufacturing process has more than one consequence; therefore, it is relatively difficult to improve the shrinkage property by changing a single parameter. For example, the changes in yarn count, stitch length and machine diameter during the fabric production to control shrinkage also affect the tightness factor, mass per unit area and width along with the shrinkage property, and also develop spirality as these all are correlated with each other. Most common methods that are used by factories for developing a new sample or upgrade existing quality are previous experience, guess work, or trial and error method that are not only expensive but also time-consuming and a waste of production resources. It is also very risky as there may not be enough time or resources to be successful. The necessity of establishing a prognostic model for forecasting the performance of a proposed fabric quality before its production has become obligate. There are three different models for predicting knitted fabric characteristics, i.e. mathematical model, statistical regression model and intelligent model. The mathematical models implemented by many researchers for predicting different properties of a textile material are very appealing since they are established on the fundamental theories of basic science, which provide a clear conception about the work process [2, 3, 12-18]. The well-developed prediction model for forecasting knitted fabric shrinkage called STARFISH has some limitations as it uses an enormous amount of data accumulated from all over the world, consequently adversely affecting the prediction performance. Moreover, while the program predicts the properties, the reference production condition and latest finishing procedure explained in STARFISH is strictly maintained for good prediction 
performance that is relatively difficult for most factories to maintain. The computational database model which has been developed in an Excel spread sheet for predicting knitted fabric shrinkage used a huge amount of data for establishing a model which is very challenging to collect as well as time-consuming. Several researchers developed models using statistical regression that are used in the relevant field [1421]. Hence, large amounts of sample data, as well as a prior assessment of the relationship between inputs and outputs, are required for constructing a statistical model. Moreover, the non-linear relationship between inputs and outputs cannot be caught by both mathematical and statistical models [22-23].

Essentially, the advent of artificial intelligent techniques such as artificial neural network (ANN) and adaptive neuro-fuzzy inference system (ANFIS) has given a new incentive in the research world for developing a prediction model. Now, based on different parameters, a lot of work has been done by many researchers to forecast knitted fabric attributes, e.g. bursting strength, pilling tendency, air permeability, thermal resistance, spirality, hand evaluation, defect classification etc, and also in the woven and apparel industry [24-30]. An enormous amount of noise free data is required in establishing the ANN and ANFIS model, which becomes very difficult and time consuming to accumulate from the textile industry $[22,23,31]$. Moreover, the ANN model works like a black box as it is not able to give precise intensification of non-linearity between input-outputs and core logic on which a decision could be made $[22,23,32]$.

Conversely, the fuzzy inference system is a very proficient modelling tool which overcomes the lacunas of ANN, ANFIS and statistical regression, as it is based on fuzzy logic that can easily interpret the knowledge of experts into a set of rules in an inference system and is focused on modes of reasoning that are fairly accurate rather than exact. The fuzzy expert system implementation is easier than other models, since it can execute the modelling operation with a small amount of experimental data in the non-linear, imprecise, vague, trial-error and complex textile domain [22-25, 31-33]. Therefore, in this current research, the predictions of mass per unit area and shrinkage properties of a plain cotton knitted fabric were performed by constructing a fuzzy knowledge-based model as it is more userfriendly, of low design cost and simply applicable.

\section{Methodology}

\subsection{Knitting process}

$100 \%$ cotton plain single jersey fabrics were knitted in 30 inches $(76.2 \mathrm{~cm})$ diameter, 20 gauge single jersey circular knitting machine. For constructing the fuzzy model, yarn count was considered in the English count $(\mathrm{Ne})$ system as this unit is commonly used in knitting industries. In total, seven different types of samples were made. The amount of each sample was $5 \mathrm{~kg}$. The knitting parameters that were used during the making of samples are shown in Table 1.

Table 1: Knitting parameters of experimental samples

\begin{tabular}{|c|c|c|c|}
\hline \multirow{2}{*}{$\begin{array}{c}\text { Sam- } \\
\text { ple }\end{array}$} & \multicolumn{2}{|c|}{ Yarn count } & \multirow{2}{*}{ Stitch } \\
\cline { 2 - 3 } & [tex] & $\begin{array}{c}\text { Corre- } \\
\text { sponding } \\
\text { English } \\
\text { count [Ne] }\end{array}$ & $\begin{array}{c}\text { length } \\
\text { [mm] }\end{array}$ \\
\hline 1 & 21.09 & 28 & 2.65 \\
\hline 2 & 24.61 & 24 & 2.75 \\
\hline 3 & 21.09 & 28 & 2.75 \\
\hline 4 & 19.69 & 30 & 2.75 \\
\hline 5 & 22.72 & 26 & 2.85 \\
\hline 6 & 21.09 & 28 & 2.85 \\
\hline 7 & 19.69 & 30 & 2.85 \\
\hline
\end{tabular}

\subsection{Pre-treatment and finishing procedure}

Scouring and bleaching of cotton knitted fabrics were done in a common bath. The process was carried on a sample dyeing machine (Sclavos, Greece) using detergent $0.5 \mathrm{~g} / \mathrm{l}$ (Ecowett JTLF, Vijol, India), anti-creasing agent $0.5 \mathrm{~g} / \mathrm{l}$ (Lenetol PAC, Croda, India), sequestering agent $0.3 \mathrm{~g} / \mathrm{l}$ (Eco SQ-114FE, Jintex, Taiwan), stabilizing agent $0.2 \mathrm{~g} / \mathrm{l}$ (Eco ST201, Jintex, Taiwan), sodium carbonate $\left(\mathrm{Na}_{2} \mathrm{CO}_{3}\right)$ $5 \mathrm{~g} / \mathrm{l}$, sodium hydroxide $(\mathrm{NaOH}) 0.5 \mathrm{~g} / \mathrm{l}$, hydrogen peroxide $50 \% 4 \mathrm{~g} / \mathrm{l}$. Afterwards, the fabric samples were washed. Finally, $1 \mathrm{~g} / \mathrm{l}$ acetic acid $\left(\mathrm{CH}_{3} \mathrm{COOH}\right)$ and $0.2 \mathrm{~g} / \mathrm{l}$ peroxide killing agent (peroxidase enzyme) were applied onto fabrics for neutralization. After the scouring and bleaching, the samples were slit in a Bianco sliting machine. Then, they were passed in a Brukner stenter machine at $13 \mathrm{~m} / \mathrm{min}$ speed at $150^{\circ} \mathrm{C}$ with the constant width of $1.6 \mathrm{~m}$ (63 inches). To observe the effect of overfeed percentage on mass per unit area and dimensional stability 
of a knitted fabric, each sample was processed with five different overfeed percentages, e.g. 10\%, $20 \%$, $30 \%, 40 \%, 50 \%$ of the stenter machine. Therefore, $7 \times 5=35$ samples were obtained. Before the testing, all samples were kept on a flat surface for conditioning for at least 24 hours. Standard atmospheric conditions, i.e. relative humidity $(65 \pm 2) \%$ and temperature $(20 \pm 2){ }^{\circ} \mathrm{C}$, were properly maintained during

Table 2: Experimental results of fabric mass per unit area (GSM) and shrinkage properties

\begin{tabular}{|c|c|c|c|c|c|c|}
\hline \multirow{2}{*}{$\begin{array}{l}\text { Sample } \\
\text { no. }\end{array}$} & \multicolumn{2}{|c|}{$\begin{array}{c}\text { Knitting } \\
\text { parameters }\end{array}$} & \multirow{2}{*}{$\begin{array}{c}\text { Finishing } \\
\text { parameter } \\
\text { Overfeed in } \\
\text { stenter } \\
\text { machine [\%] }\end{array}$} & \multirow{2}{*}{$\begin{array}{c}\text { GSM } \\
{\left[\mathrm{g} / \mathrm{m}^{2}\right]}\end{array}$} & \multicolumn{2}{|c|}{ Shrinkage [\%] } \\
\hline & $\begin{array}{c}\text { Yarn } \\
\text { count } \\
{[\mathrm{Ne}]}\end{array}$ & $\begin{array}{r}\text { Stitch } \\
\text { length } \\
{[\mathrm{mm}]}\end{array}$ & & & $\begin{array}{c}\text { Lengthwise } \\
\text { shrinkage (LS) }\end{array}$ & $\begin{array}{c}\text { Widthwise } \\
\text { shrinkage (WS) }\end{array}$ \\
\hline S1 & 26 & 2.85 & 10 & 133 & -18 & -1 \\
\hline S2 & 28 & 2.85 & 10 & 119 & -20 & -7 \\
\hline S3 & 30 & 2.85 & 10 & 111 & -20 & -6 \\
\hline S4 & 26 & 2.85 & 20 & 141 & -14 & -2 \\
\hline S5 & 28 & 2.85 & 20 & 136 & -11 & -5 \\
\hline S6 & 30 & 2.85 & 20 & 132 & -15 & -5 \\
\hline S7 & 26 & 2.85 & 30 & 150 & -12 & -1 \\
\hline S8 & 28 & 2.85 & 30 & 138 & -11 & -3 \\
\hline S9 & 30 & 2.85 & 30 & 135 & -11 & -5 \\
\hline S10 & 26 & 2.85 & 40 & 150 & -10 & -4 \\
\hline S11 & 28 & 2.85 & 40 & 144 & -10 & -3 \\
\hline S12 & 30 & 2.85 & 40 & 134 & -10 & -4 \\
\hline S13 & 26 & 2.85 & 50 & 154 & -11 & -2 \\
\hline S14 & 28 & 2.85 & 50 & 148 & -8 & -4 \\
\hline S15 & 30 & 2.85 & 50 & 135 & -9 & -4 \\
\hline S16 & 24 & 2.75 & 10 & 180 & -14 & -2 \\
\hline S17 & 28 & 2.75 & 10 & 125 & -17 & -8 \\
\hline S18 & 30 & 2.75 & 10 & 116 & -18 & -7 \\
\hline S19 & 24 & 2.75 & 20 & 185 & -9 & -1 \\
\hline S20 & 28 & 2.75 & 20 & 140 & $\begin{array}{l}-10 \\
\end{array}$ & -6 \\
\hline S21 & 30 & 2.75 & 20 & 135 & -10 & -6 \\
\hline S22 & 24 & 2.75 & 30 & 191 & -7 & 0 \\
\hline S23 & 28 & 2.75 & 30 & 144 & -9 & -2 \\
\hline S24 & 30 & 2.75 & 30 & 138 & -10 & -4 \\
\hline S25 & 24 & 2.75 & 40 & 195 & -4 & 0 \\
\hline S26 & 28 & 2.75 & 40 & 150 & -6 & -3 \\
\hline S27 & 30 & 2.75 & 40 & 140 & -6 & -2 \\
\hline S28 & 24 & 2.75 & 50 & 205 & -2 & 1 \\
\hline S29 & 28 & 2.75 & 50 & 152 & -4 & -4 \\
\hline S30 & 30 & 2.75 & 50 & 148 & -5 & -2 \\
\hline S31 & 28 & 2.65 & 10 & 135 & -12 & -5 \\
\hline S32 & 28 & 2.65 & 20 & 148 & -6 & -5 \\
\hline S33 & 28 & 2.65 & 30 & 154 & -5 & -4 \\
\hline S34 & 28 & 2.65 & 40 & 160 & -3 & -1 \\
\hline S35 & 28 & 2.65 & 50 & 165 & 0 & 0 \\
\hline
\end{tabular}


the conditioning of samples. After the washing, the length- and widthwise shrinkage properties of each sample were investigated according to AATCC-TM 135 [34]. The GSM of 35 samples was measured in line with ISO 3801 [35] and weighed on an electronic weighing machine. The experimental results of all 35 samples are listed in Table 2.

\subsection{Establishment of fuzzy prediction model}

The fuzzy prediction model was constructed by using three different variables, namely stitch length (SL), yarn count (YC) and overfeed (OF) percentage in a stenter machine as input variables, and mass per unit area (GSM), length- and widthwise shrinkage (LS, WS) of knitted fabrics as output variables. The selected variables have a great influence on the shrinkage of knitted fabrics. The proposed fuzzy prediction model of fabric shrinkage and GSM was developed by using a fuzzy logic toolbox from MATLAB (version 8.2.0.701). The construction of the fuzzy prediction model for LS, WS and GSM of knitted fabrics is illustrated in Figure 1.

For fuzzification, input and output variables were classed into some probable linguistic subsets for the fuzzy expert system being able to trace small changes in output variables with any variation of input variables. The linguistic fuzzy sets for input-output parameters are given in Table 3.

Among all the membership functions, the triangular-shaped membership functions are very popular due to their simplicity and precision. In this research, triangular functions were applied for both input and output variables as variables can easily be described by them [36].

Mamdani max-min fuzzy inference mechanism assures a linear interpolation of outputs between the rules $[24,25]$. Therefore, the model is constructed by using this mechanism. Theoretically, there could be $4 \times 3 \times 5=60$ fuzzy rules as the input variable SL has 3 linguistic levels, Count

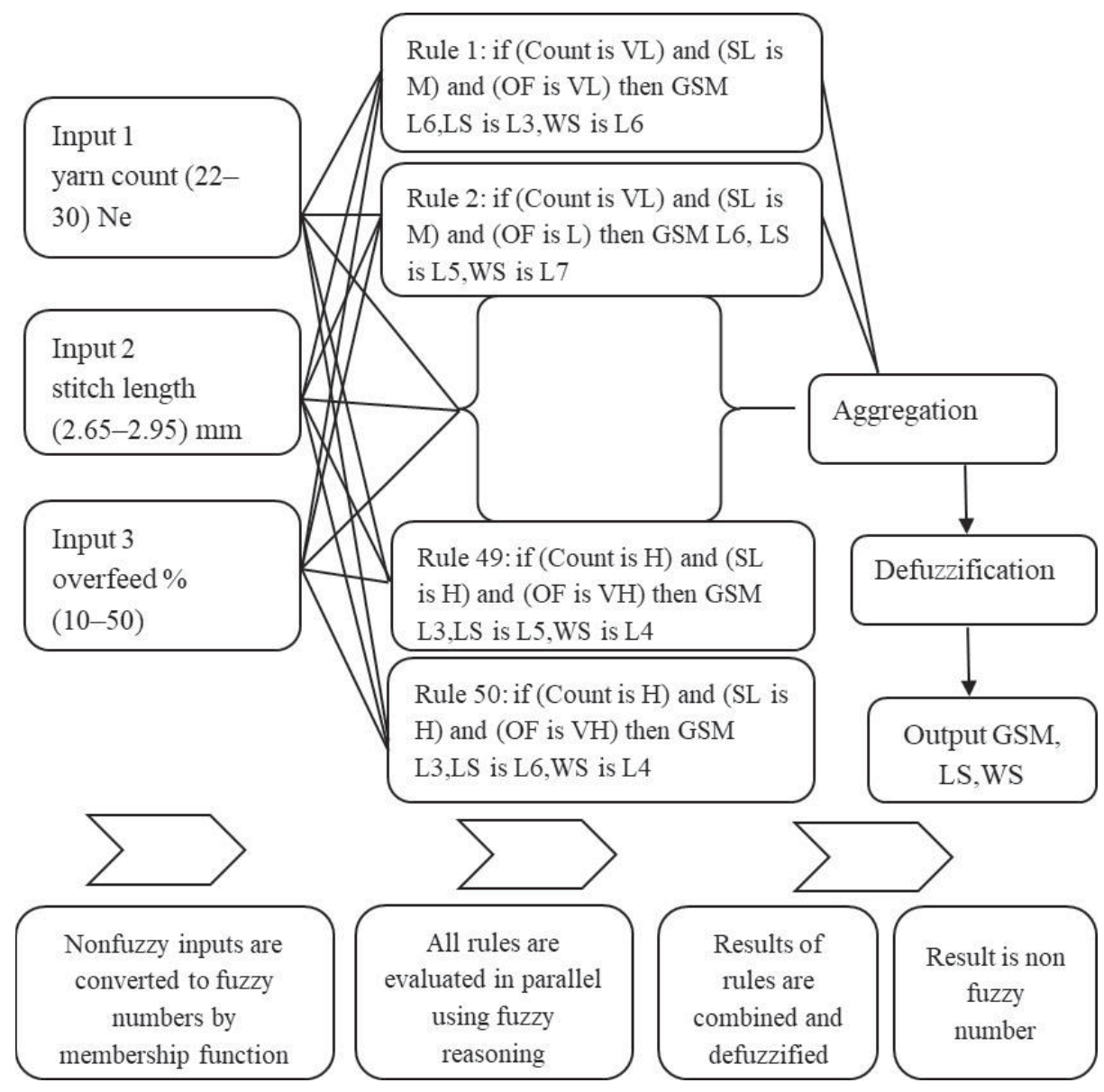

Figure 1: Construction of fuzzy intelligent modelling for fabric shrinkage and GSM 
Table 3: Linguistic fuzzy sets for input-output variables

\begin{tabular}{|l|c|c|l|}
\hline \multicolumn{1}{|c|}{ Input variables } & Unit & Range & \multicolumn{1}{c|}{ Linguistic fuzzy set } \\
\hline Stitch length (SL) & $\mathrm{mm}$ & $2.65-2.95$ & Low, Medium, High \\
\hline Yarn count (YC) & $\mathrm{Ne}$ & $22-30$ & Very low, Low, Medium, High \\
\hline $\begin{array}{l}\text { Overfeed in stenter } \\
\text { machine (OF) }\end{array}$ & $\%$ & $10-50$ & Very low, Low, Medium, High, Very high \\
\hline \multicolumn{1}{|c|}{ Output variables } & Unit & Range & \multicolumn{1}{c|}{ Linguistic fuzzy set } \\
\hline $\begin{array}{l}\text { Lengthwise shrinkage } \\
\text { (LS) }\end{array}$ & $\%$ & -20 to -2 & $\begin{array}{l}\text { Level 1, Level 2, Level 3, Level 4, Level 5, } \\
\text { Level 6, Level 7, Level 8, Level 9 }\end{array}$ \\
\hline $\begin{array}{l}\text { Widthwise shrinkage } \\
\text { (WS) }\end{array}$ & $\%$ & -8 to +1 & $\begin{array}{l}\text { Level 1, Level 2, Level 3, Level 4, Level 5, } \\
\text { Level 6, Level 7, Level 8 }\end{array}$ \\
\hline $\begin{array}{l}\text { Mass per unit area (GSM) } \\
\text { Level 1, Level 2, Level 3, Level 4, Level 5, } \\
\text { Level 6, Level 7, Level 8 }\end{array}$ \\
\hline
\end{tabular}

has 4 linguistic levels and Overfeed percentage in the stenter machine has 5 linguistic levels [23]. However, on the basis of expert knowledge and prior experience, only 50 rules have been used which make the fuzzy expert system simple and more easy to use $[22,23]$. Some examples of established fuzzy rules are revealed in Table 4.

For instance, Rule 1 and Rule 18 are described as follows:

Rule 1: If Count $=V L$ and SL $=M$, and OF $=V L$, then GSM $=\mathrm{L} 6, \mathrm{LS}=\mathrm{L} 3$ and WS $=\mathrm{L} 4$, i.e. if Count is Very low, Stitch length is Medium and Overfeed percentage is Very low, then GSM is Level 6, Lengthwise shrinkage percentage is Level 3 and Widthwise shrinkage is Level 6.

Rule 18: If Count $=\mathrm{L}, \mathrm{SL}=\mathrm{H}$, and $\mathrm{OF}=\mathrm{M}$, then $\mathrm{GSM}=\mathrm{L} 4, \mathrm{LS}=\mathrm{L} 4$ and WS $=\mathrm{L} 7$, i.e. if Count is Low, Stitch length is High and Overfeed percentage is Medium, then GSM is Level 4, Lengthwise shrinkage percentage is Level 4 and Widthwise shrinkage is Level 7.

Each linguistic value that is used in each input variable has a level of a membership. Equations 1-6 were applied for fuzzification of input variables and the membership functions are also demonstrated in Figures 2-7:

$$
\begin{aligned}
& \text { SL }\left(i_{1}\right)=\left\{\begin{array}{l}
i_{1} ; 2.65 \leq i_{1} \leq 2.95 \\
0 ; \text { Otherwise }
\end{array}\right. \\
& \text { YC }\left(i_{2}\right)=\left\{\begin{array}{l}
i_{2} ; 22 \leq i_{2} \leq 30 \\
0 ; \text { Otherwise }
\end{array}\right. \\
& \text { OF }\left(i_{3}\right)=\left\{\begin{array}{l}
i_{3} ; 10 \leq i_{3} \leq 50 \\
0 ; \text { Otherwise }
\end{array}\right. \\
& \text { LS }\left(O_{1}\right)=\left\{\begin{array}{l}
O_{1} ;-20 \leq O_{1} \leq-2 \\
0 ; \text { Otherwise }
\end{array}\right. \\
& \text { WS }\left(O_{2}\right)=\left\{\begin{array}{l}
O_{2} ;-8 \leq O_{2} \leq 1 \\
0 ; \text { Otherwise }
\end{array}\right. \\
& \operatorname{GSM}\left(O_{3}\right)=\left\{\begin{array}{l}
O_{3} ; 110 \leq O_{3} \leq 210 \\
0 ; \text { Otherwise }
\end{array}\right.
\end{aligned}
$$

Table 4: Developed fuzzy rules for modelling

\begin{tabular}{|c|c|c|c|c|c|c|}
\hline \multirow{2}{*}{ Rules } & \multicolumn{3}{|c|}{ Input variables } & \multicolumn{3}{c|}{ Output variables } \\
\cline { 2 - 7 } & YC & SL & OF & GSM & LS & WS \\
\hline Rule 1 & VL & M & VL & L6 & L3 & L6 \\
\hline$\cdot$ & $\cdot$ & $\cdot$ & $\cdot$ & $\cdot$ & $\cdot$ & $\cdot$ \\
$\cdot$ & $\cdot$ & $\cdot$ & $\cdot$ & $\cdot$ & $\cdot$ & $\cdot$ \\
\hline Rule 18 & L & H & M & L4 & L4 & L7 \\
\hline$\cdot$ & $\cdot$ & $\cdot$ & $\cdot$ & $\cdot$ & $\cdot$ & $\cdot$ \\
$\cdot$ & $\cdot$ & $\cdot$ & $\cdot$ & $\cdot$ & $\cdot$ & $\cdot$ \\
$\cdot$ & $\cdot$ & $\cdot$ & $\cdot$ & $\cdot$ & $\cdot$ & $\cdot$ \\
\hline Rule 50 & H & H & VH & L3 & L6 & L4 \\
\hline
\end{tabular}




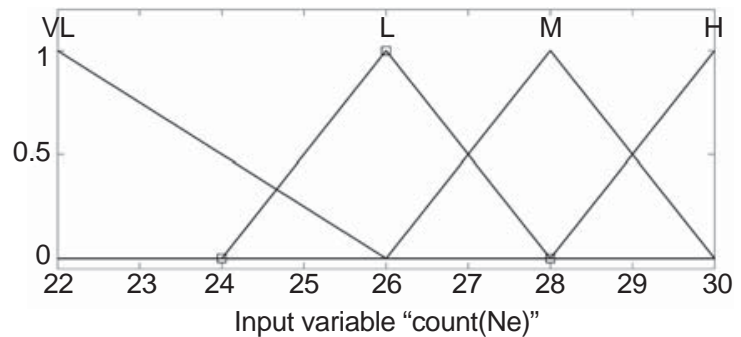

Figure 2: Membership function of input variable count $(\mathrm{Ne})$

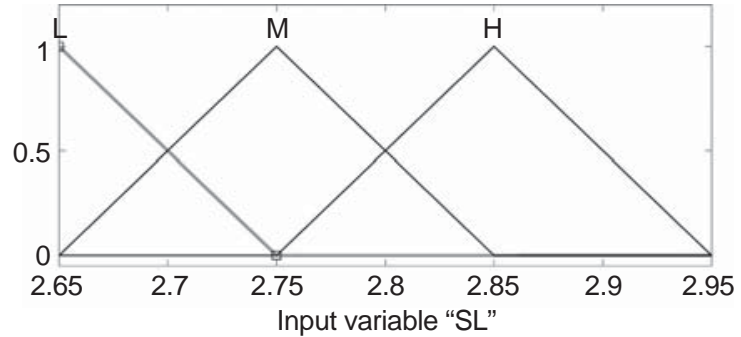

Figure 3: Membership function of input variable stitch length (SL)

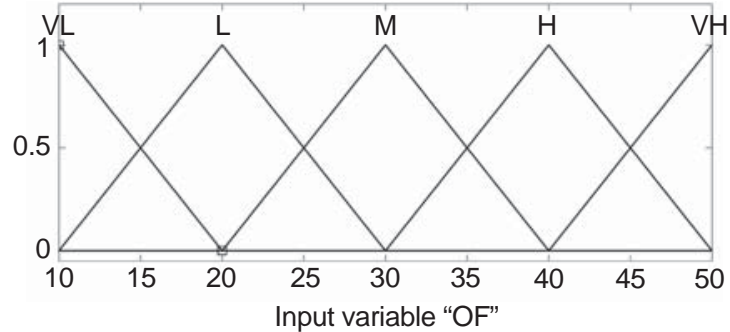

Figure 4: Membership function of input variable overfeed percentage (OF)

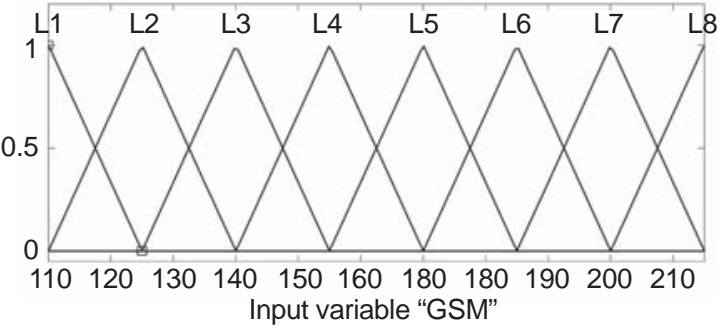

Figure 5: Membership function of output variable GSM

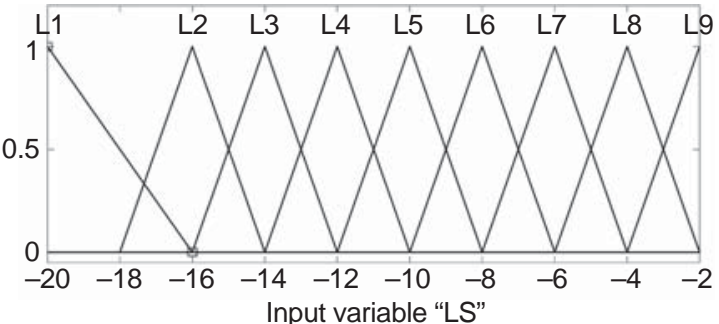

Figure 6: Membership function of output variable lengthwise shrinkage (LS)

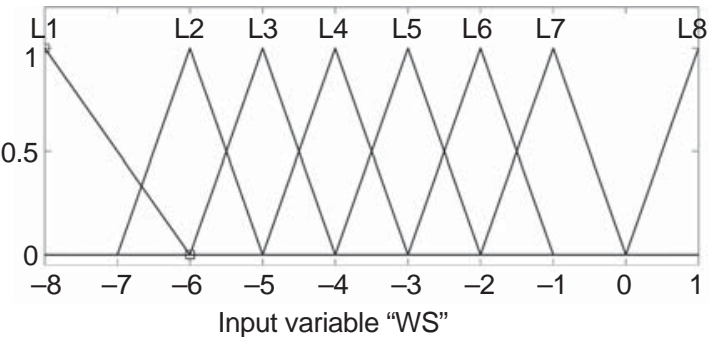

Figure 7: Membership function of output variable widthwise shrinkage (WS)

To elucidate the fuzzification process, linguistic terms for triangular membership functions can be interpreted through equation 7 [37]:

$\mu_{\text {triangle }}\left(x, c_{1}, c_{2}, c_{3}\right)=\left\{\begin{array}{c}\frac{x-c_{1}}{c_{2}-c_{1}} ; c_{1} \leq x \leq c_{2} \\ \frac{c_{2}-x}{c_{3}-c_{2}} ; c_{2} \leq x \leq c_{3} \\ 0 ; x \geq c_{3}\end{array}\right.$

The linguistic expression and membership function of stitch length, yarn count and overfeed percentage found from the established rules and the formula above is presented in equations below (equations 8-15) [31, 32, 37]:

$\mu_{M}(S L)=\left\{\begin{array}{c}\frac{i_{1}-2.65}{2.75-2.65} ; 2.65 \leq i_{1} \leq 2.75 \\ \frac{2.85-i_{1}}{2.85-2.75} ; 2.75 \leq i_{1} \leq 2.85 \\ 0 ; i_{1} \geq 2.85\end{array}\right.$

$\mu_{M}(S L)=\left\{\frac{0}{2.65}+\frac{0.5}{2.70}+\frac{1}{2.75} \ldots+\frac{0.5}{2.80}+\frac{0}{2.85}\right\}$

$\mu_{H}(S L)=\left\{\begin{array}{c}\frac{i_{1}-2.75}{2.85-2.75} ; 2.75 \leq i_{1} \leq 2.85 \\ \frac{2.95-i_{1}}{2.95-2.85} ; 2.85 \leq i_{1} \leq 2.95 \\ 0 ; i_{1} \geq 2.95\end{array}\right.$

$\mu_{H}(S L)=\left\{\frac{0}{2.75}+\frac{0.5}{2.80}+\frac{1}{2.85} \ldots+\frac{0.5}{2.90}+\frac{0}{2.95}\right\}$

$\mu_{L}($ Count $)=\left\{\begin{array}{c}\frac{i_{2}-24}{26-24} ; 24 \leq i_{2} \leq 26 \\ \frac{28-i_{2}}{28-26} ; 26 \leq i_{2} \leq 28 \\ 0 ; i_{2} \geq 28\end{array}\right.$ 
$\mu_{L}($ Count $)=\left\{\frac{0}{24}+\frac{0.5}{25}+\frac{1}{26} \ldots+\frac{0.5}{27}+\frac{0}{28}\right\}$

$\mu_{L}($ Count $)=\left\{\begin{array}{c}\frac{i_{2}-26}{28-26} ; 26 \leq i_{2} \leq 28 \\ \frac{30-i_{2}}{30-28} ; 28 \leq i_{2} \leq 30 \\ 0 ; i_{2} \geq 30\end{array}\right.$

$\mu_{M}($ Count $)=\left\{\frac{0}{26}+\frac{0.5}{27}+\frac{1}{28} \ldots+\frac{0.5}{29}+\frac{0}{30}\right\}$

In the same way, the linguistic expression and membership function of other variables was determined. Among different defuzzification methods, the centre of gravity (COG) defuzzification method was used for converting the fuzzy output into non-fuzzy crisp numeric value $[22,37]$. The truth degrees $(\mu)$ of each rule are enumerated with the help of the min and by taking the max between active rules $[32,38]$. It can be explained by considering the following example, for crisp input $\mathrm{SL}=2.8$, count $=26$ and $\mathrm{OF}=30 \%$, the rules 13 and 18 will be fired. The truth values $(\alpha)$ of the two rules are given as:

$$
\begin{aligned}
\alpha_{13} & =\min \{\mu M(\mathrm{SL}), \mu L(\text { count }), \mu M(\mathrm{OF})\}= \\
& =\min (0.5,1,1)=0.5, \\
\alpha_{18} & =\min \{\mu H(\mathrm{SL}), \mu L(\text { count }), \mu M(\mathrm{OF})\}= \\
& =\min (0.5,1,1)=0.5 .
\end{aligned}
$$

The membership function was calculated according to the Mamdani max-min inference system such as $\max \left(\alpha_{13}, \alpha_{18}\right)=0.5$.

Then, the crisp output was enumerated. Hossain et al. [32] alluded that the crisp decision obtained from a system, the output of which is fuzzy by showing the output in a single scalar quantity. In this case, LScrisp (Output) was enumerated by multiplying the output membership values with their corresponding singleton values followed by dividing the obtained value by the sum of membership values which is shown in equation $16[32,37,38]$ :

$L S^{c r i s p}=\frac{\sum_{i} \operatorname{ai\mu }(i)}{\sum_{i} \mu(i)}$

where $a_{i}$ is the spot of the singleton in the $\mathrm{i}^{\text {th }}$ universe and $\mu_{(i)}$ is the firing strength of the truth values of rule i $[22,32,37,38]$.
The crisp output of LS was calculated by using equation (16) as $-10 \%$ and widthwise shrinkage $-1.5 \%$, as shown in Figure 8. The calculation of LS is given below.

$\mathrm{COG}=\frac{-(13+11+9+7) \times 0.5}{0.5+0.5+0.5+0.5}=-10$

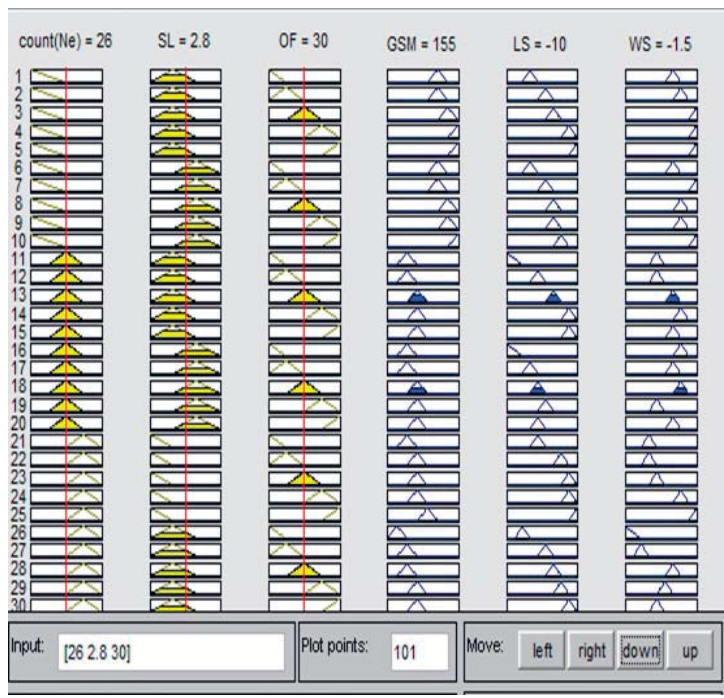

Figure 8: Rule viewer of fuzzy inference system

\subsection{Validation of prediction ability}

The proposed model was investigated according to the global prediction error such as mean absolute error percentage (MAEP) and coefficient of determination $\left(R^{2}\right)$ for determining the prediction ability of the model. The formulas of accuracy measurements are given in equations 17-19 [31, 32, 37-39]:

$R^{2}=1-\left(\frac{\sum_{i=1}^{i=N}\left(E_{a}-E_{p}\right)^{2}}{\sum_{\mathrm{i}=1}^{\mathrm{i}=N}\left(E_{a}-E_{M}\right)^{2}}\right)$

$R M S=\sqrt{\frac{\sum_{i=1}^{i=N}\left(E_{a}-E_{p}\right)^{2}}{N}}$

$M A E P=\frac{1}{N} \sum_{i=1}^{i=N}\left(\frac{\left|E_{a}-E_{p}\right|}{E_{a}} \times 100\right)$

where $E_{\mathrm{a}}$ is actual result, $E_{\mathrm{p}}$ is predicted result, $E_{\mathrm{m}}$ is mean value and $N$ represents the number of the pattern. 


\section{Results and discussion}

\subsection{Influence of input variables on GSM}

The impact of count, stitch length and overfeed percentage on fabric GSM was shown in Figures

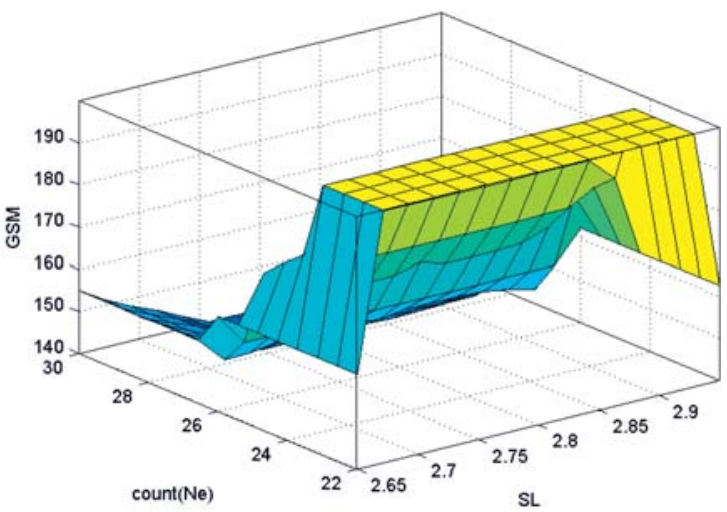

Figure 9: Surface plot exhibiting dominance of titch length and Count on GSM (Count-SL)

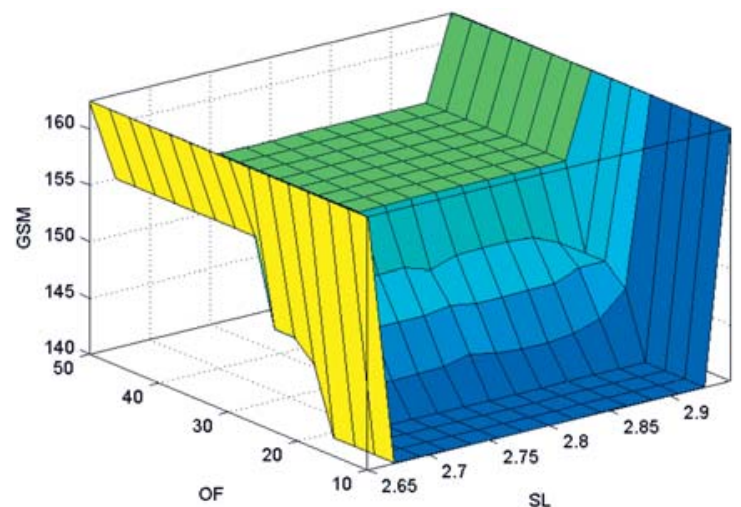

Figure 10: Surface plot viewing impact of stitch length and overfeed percentage on GSM (OF-SL)

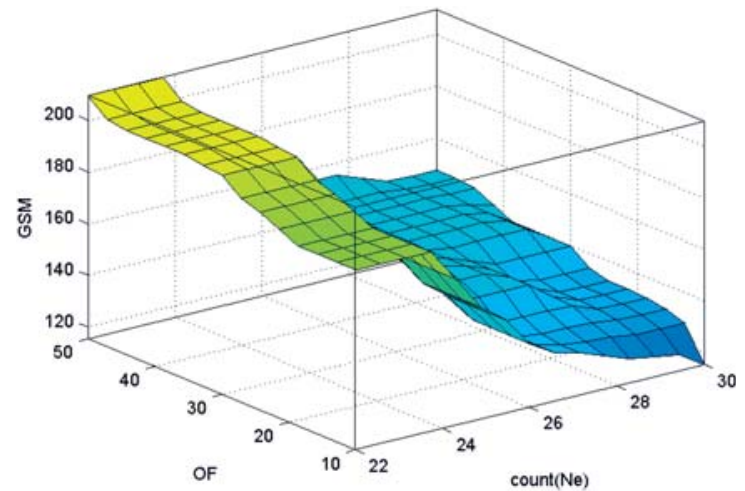

Figure 11: Surface plot showing effect of count and overfeed percentage on GSM (Count-SL)
9-11. It can be seen in Figure 9 that finer yarn count coupled with lower stitch length exhibited higher fabric GSM. An approximately $25-30 \%$ increment in fabric GSM was found for 7\% drop off in stitch length. This might have occurred as lower stitch length increases stitch density in the unit area, which then resulted in heavier weight of a fabric [40]. Moreover, Figure 9 also showed that yarn getting finer by up to $30 \mathrm{Ne}$, stitch length from 2.7 to $2.9 \mathrm{~mm}$ caused lighter GSM in the knitted fabric. It can be seen in Figures 10 and 11 that lower OF did not substantially affect fabric weight whereas at OF above $20 \%$, the GSM of the knitted fabric increased dramatically with the rise of OF. When the OF was increased from $20 \%$ to $35 \%$ in stenter, about $15 \%$ fabric GSM was increased, which was probably due to the accumulation of the fabric in the feeding area of the stenter machine, which raised the density of the fabric [41]. However, fabric GSM came to an optimal level in between 35 to 50\% OF. Figure 11 shows that GSM increased to around $73 \%$ and around $37 \%$ with thicker yarn and higher overfeed percentage, respectively.

\subsection{Influence of input variables on lengthwise shrinkage}

Effect of overfeed percentage, count and stitch length on lengthwise shrinkage is shown in Figures 12-14. Figure 12 depicts that LS was improved with the increase of OF and vice versa. Initially, no significant effect was observed in LS when increasing SL. However, LS was highly affected by OF valued near $20 \%$ and upwards. Only SL $(2.8 \mathrm{~mm}$ to $2.9 \mathrm{~mm}$ ) had an individual effect on LS which improved steadily with the increase of OF. LS was improved at around $75 \%$ for elevating the overfeed from $20 \%$ to $50 \%$ within the range $2.65 \mathrm{~mm}$ to $2.75 \mathrm{~mm} \mathrm{SL}$, while no significant effect was observed for $10 \%$ OF. Nevertheless, in the mid-range SL $(2.7-2.8 \mathrm{~mm})$, LS was improved by about $40 \%$ for increasing overfeed from $10 \%$ to $50 \%$. It can also be seen in Figure 13 that the effect of yarn count on the length-wise shrinkage property was not linear but OF showed a linear relationship with the LS property of the fabric. LS showed relatively better performance for coarser yarn than finer as it was enhanced by around $67 \%$ when increasing overfeed from $10 \%$ to $50 \%$ in coarser count $(22-24 \mathrm{Ne})$. Very high OF ( $40 \%$ to $50 \%)$ upgraded shrinkage 
property for both coarser and finer yarn count [42]. No notable improvement in lengthwise shrinkage was observed in Figure 14 for increasing stitch length in the range $2.7-2.9 \mathrm{~mm}$ for thicker

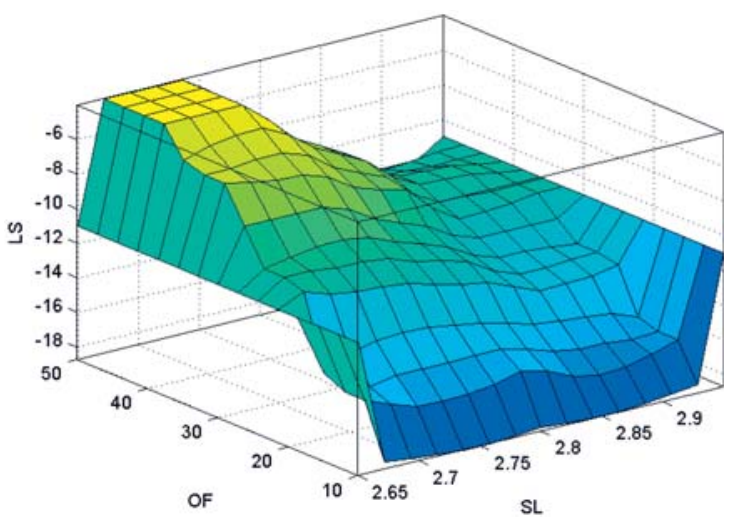

Figure 12: Surface plot exhibiting impact of SL and Overfeed percentage on LS (OF-SL)

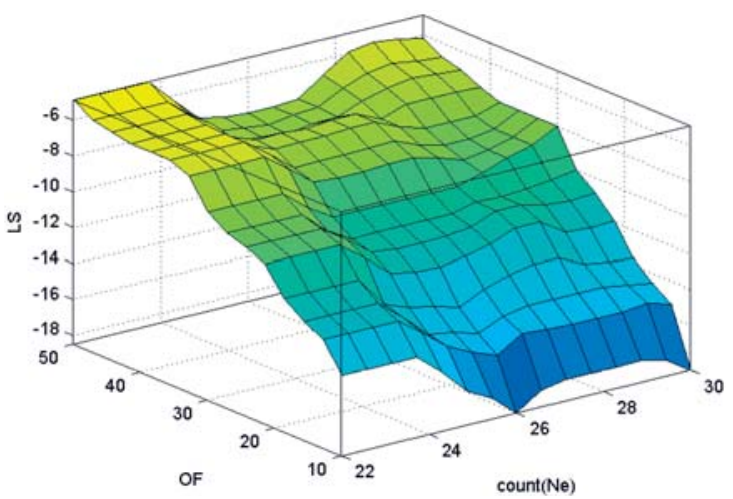

Figure 13: Surface plot exhibiting impact of Count and Overfeed percentage on LS (OF-Count)

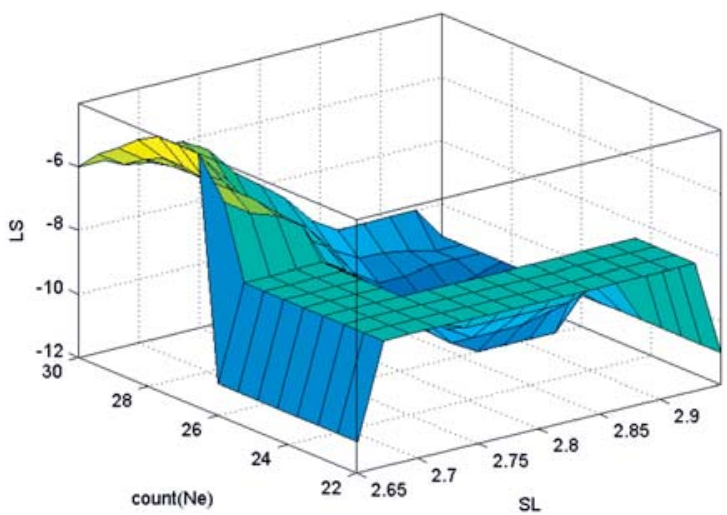

Figure 14: Surface plot exhibiting impact of Count and SL on LS (Count-SL) yarn count. Conversely, thinner yarn count (28-30 Ne) showed better performance in LS from 2.65 to $2.75 \mathrm{~mm} \mathrm{SL}$, whereas with the elevation of stitch length in finer yarn, the LS property declined. Specifically, in the case of $28-30 \mathrm{Ne}$ of yarn count, the increase of LS due to the increase of SL from $2.65 \mathrm{~mm}$ to $2.9 \mathrm{~mm}$ was around $60 \%$. From the overall context, this may be justified as the compact knitted structure formed by either lower SL or higher $\mathrm{OF}$ or coarser count or combination of them made the fabric more stable after the washing. Due to higher OF, the forces in the processing of a cotton fabric with lower SL and coarser count contributed to the contraction of the fabric as the forces push mechanically the knitted loops towards each other to make them closer. Hence, after the washing, the non-linear hysteresis effect caused the cotton fabric to become denser (as loops do not get enough space to shrink) and the fabric consequently became more dimensionally stable [41].

\subsection{Influence of input variables on widthwise shrinkage}

The impact of count, stitch length, overfeed percentage on widthwise shrinkage (WS) is shown in Figures 15-17. The WS of the knitted fabric improved linearly with OF and SL, which is shown in Figure 15. WS was improved by approximately $46 \%$ when overfeed was increased from $10 \%$ to $50 \%$ at $2.65 \mathrm{~mm} \mathrm{SL}$, whereas in mid-range SL $(2.7-2.8 \mathrm{~mm})$, it progressed by about $30 \%$. As lengthwise shrinkage improved at high overfeed percentage, the width of the fabric changed as well. Figure 16 revealed that though in the finer count and lower SL there was no impact on WS, the latter decreased slowly with greater SL in almost 22 to $26 \mathrm{Ne}$ count. An approximately reduction in the widthwise direction increased by $25 \%$ when SL increased from 2.7 to $2.8 \mathrm{~mm}$ for finer counts, i.e. 28 and $30 \mathrm{Ne}$. As after washing, finer yarn with high stitch length gets more space for swelling and comes close together, this lessen the width of the fabric after relaxation. Conversely, coarser yarn with high stitch length fabric showed a lower value of shrinkage in the widthwise direction, as it contained high course length and less space between loops that caused the fabric to extend in the width direction rather than shrink [42].

Lastly, Figure 17 shows that WS enhanced significantly with higher OF percentage and vice versa. The effect of $28-30 \mathrm{Ne}$ count with $10-20 \%$ OF on WS was not perceptible enough. At over $20 \%$ of OF, WS 
improved sharply in ascending order. In low-range count (22 to $24 \mathrm{Ne}$ ) with $50 \%$ OF, low WS in the fabric was found. In the light of the above context, it can be summarized that the effectiveness of stitch length, count and overfeed \% on WS was less significant for all the fabrics as they were made in the same

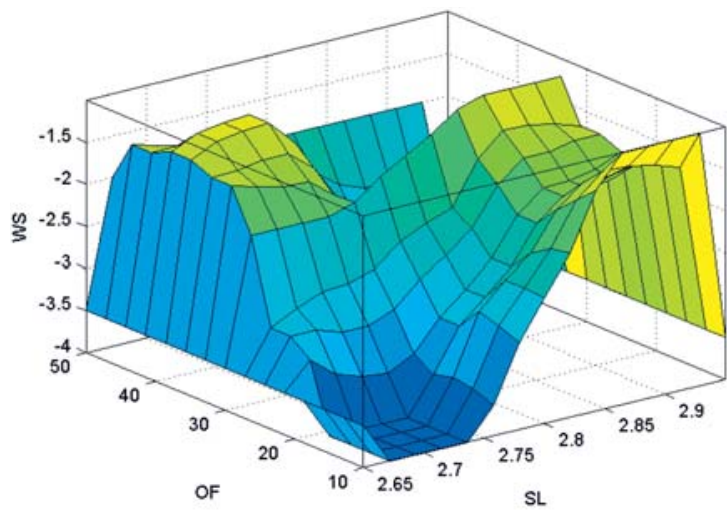

Figure 15: Surface plot showing dominance of OF and SL on WS (SL-OF)

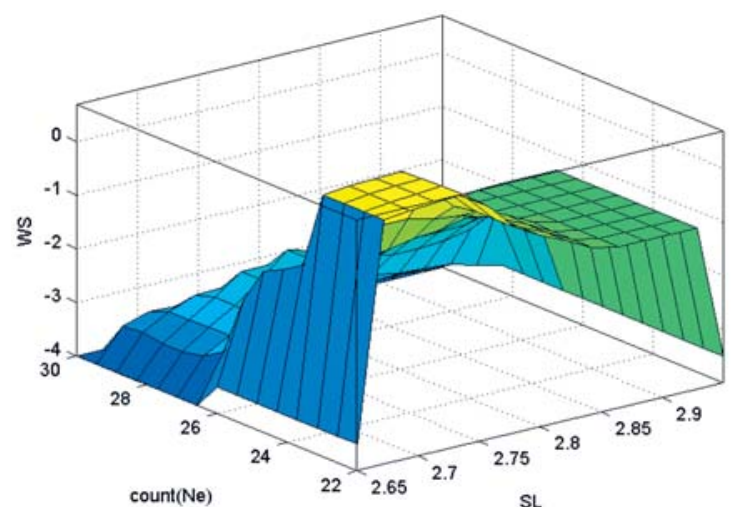

Figure 16: Control surface plot viewing impact of Count and SL on WS (SL-count)

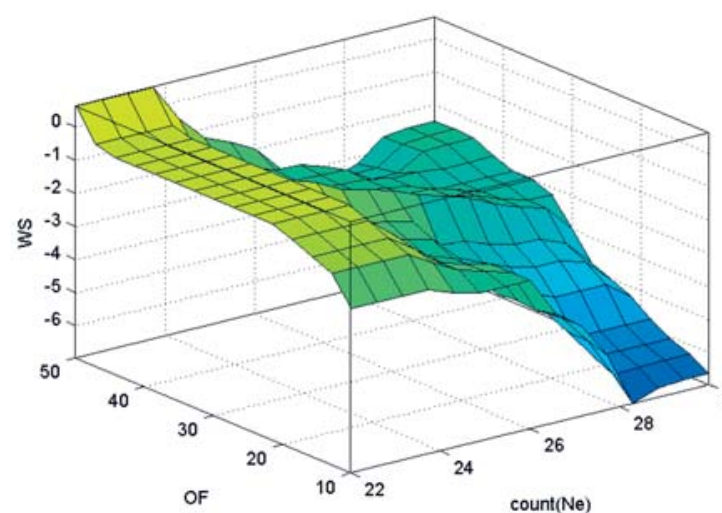

Figure 17: Surface plot viewing impact of count and OF on WS (OF-Count) diameter of the knitting machine and passed in a stenter, keeping constant width.

\subsection{Justification of fuzzy prediction model}

In this study, the proposed model was verified by conducting 15 new experiments. The prediction accuracy of the developed model was estimated by enumerating the coefficient of determination $\left(\mathrm{R}^{2}\right)$ and mean absolute error percentage (MAEP) between the real and prognosticated values of fabric GSM, LS and WS. A comparison between the predicted values obtained from the established fuzzy logic model and the empirical values is shown in Table 5.

The correlation between prognosticated and actual values of fabric GSM, LS and WS in different conditions is depicted in Figures 18-20. It was observed that the obtained coefficients of determination $\left(\mathrm{R}^{2}\right)$ from the prognosticated and actual values of GSM, LS and WS were $0.975,0.9903$ and 0.99 . This means that the proposed model can describe up to $99.7 \%$ of the total variability of fabric GSM, $99.5 \%$ of the total changeability of LS and $98.5 \%$ of the total variation in WS. Again, the absolute error indicates a deviation between the actual value and predicted value, and the requirement of absolute error value is to be zero. The mean absolute errors (MAEP) between the experimental and predicted value were 1.85, 3.10 and 5.15. Therefore, the validation of predicted values with the experimental values suggests that the developed fuzzy intelligent model may possess very good applicability in industrial scale for predicting the shrinkage and GSM of knitted fabrics.

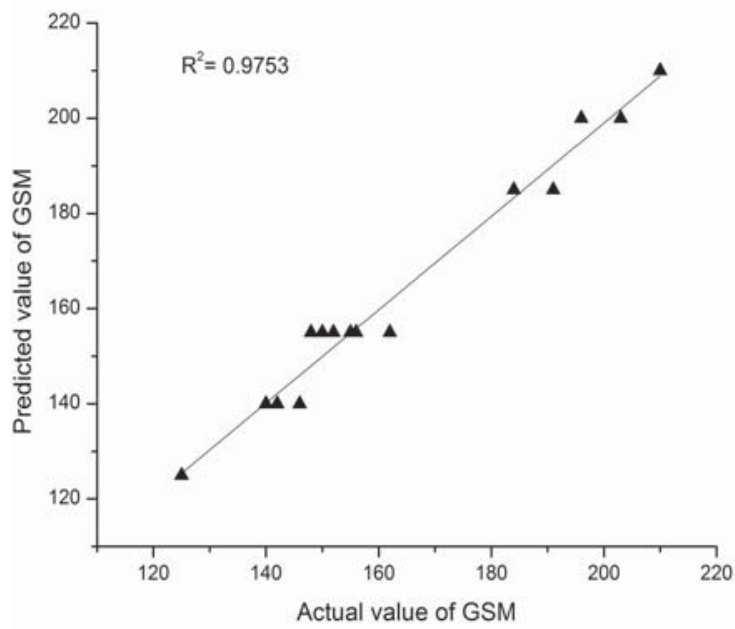

Figure 18: Correlation between actual and predicted values of GSM of single jersey cotton knitted fabric 
Table 5: Comparisons of actual and predicted values of GSM, LS and WS of single jersey fabric

\begin{tabular}{|c|c|c|c|c|c|c|c|c|c|c|c|c|}
\hline $\begin{array}{c}\text { Trial } \\
\text { no. }\end{array}$ & $\begin{array}{c}\mathrm{SL} \\
{[\mathrm{mm}]}\end{array}$ & $\begin{array}{c}\mathrm{YC} \\
{[\mathrm{Ne}]}\end{array}$ & $\begin{array}{l}\text { OF } \\
{[\%]}\end{array}$ & $\begin{array}{c}\text { Actual } \\
\text { GSM }\end{array}$ & $\begin{array}{c}\text { Pre- } \\
\text { dicted } \\
\text { GSM }\end{array}$ & $\begin{array}{c}\text { GSM } \\
\mathrm{AE}^{\mathrm{a})} \\
{[\%]} \\
\end{array}$ & $\begin{array}{l}A v^{b)} \text { of } \\
\text { LS [\%] }\end{array}$ & $\begin{array}{c}\mathrm{PV}^{\mathrm{c})} \text { of } \\
\mathrm{LS} \%\end{array}$ & $\begin{array}{c}\text { LS AE } \\
{[\%]}\end{array}$ & $\begin{array}{c}\text { Actual } \\
\text { WS } \\
{[\%]}\end{array}$ & $\begin{array}{c}\text { Predict- } \\
\text { ed WS } \\
{[\%]}\end{array}$ & $\begin{array}{r}\text { WS AE } \\
{[\%]}\end{array}$ \\
\hline $\mathrm{T} 1$ & 2.65 & 30 & 10 & 125 & 125 & 0.00 & -12.5 & -12 & 4.00 & -6 & -6 & 0.00 \\
\hline $\mathrm{T} 2$ & 2.65 & 30 & 20 & 142 & 140 & 1.41 & -8 & -8 & 0.00 & -6 & -6 & 0.00 \\
\hline T3 & 2.65 & 30 & 30 & 148 & 155 & 4.73 & -6 & -6 & 0.00 & -4 & -4 & 0.00 \\
\hline $\mathrm{T} 4$ & 2.65 & 30 & 40 & 152 & 155 & 1.97 & -4 & -4 & 0.00 & -2 & -2 & 0.00 \\
\hline T5 & 2.65 & 30 & 50 & 155 & 155 & 0.00 & -2.5 & -2.61 & 4.40 & -1 & -1 & 0.00 \\
\hline T6 & 2.75 & 26 & 10 & 140 & 140 & 0.00 & -18 & -18.7 & 3.89 & -4 & -4 & 0 \\
\hline $\mathrm{T} 7$ & 2.75 & 26 & 20 & 146 & 140 & 4.11 & -12 & -12 & 0.00 & -4 & -4 & 0 \\
\hline T8 & 2.75 & 26 & 30 & 150 & 155 & 3.33 & -7 & -8 & 14.29 & -2 & -2 & 0 \\
\hline T9 & 2.75 & 26 & 40 & 156 & 155 & 0.64 & -5 & -4 & 20.00 & -1 & -1 & 0 \\
\hline T10 & 2.75 & 26 & 50 & 162 & 155 & 4.32 & -4 & -4 & 0.00 & -2 & -2 & 0 \\
\hline T11 & 2.85 & 22 & 10 & 184 & 185 & 0.54 & -14 & -14 & 0.00 & -2 & -2 & 0.00 \\
\hline $\mathrm{T} 12$ & 2.85 & 22 & 20 & 191 & 185 & 3.14 & -10 & -10 & 0.00 & 0.5 & 0.69 & 38.00 \\
\hline $\mathrm{T} 13$ & 2.85 & 22 & 30 & 196 & 200 & 2.04 & -8 & -8 & 0.00 & -1 & -1 & 0.00 \\
\hline T14 & 2.85 & 22 & 40 & 203 & 200 & 1.48 & -8 & -8 & 0.00 & -1 & -1 & 0.00 \\
\hline T15 & 2.85 & 22 & 50 & 210 & 210 & 0.00 & -6 & -6 & 0.00 & 0.5 & 0.69 & 39.20 \\
\hline \multicolumn{7}{|c|}{ Mean absolute error (MAEP) } & \multicolumn{2}{|c|}{1.85} & \multicolumn{2}{|c|}{3.10} & \multicolumn{2}{|c|}{5.15} \\
\hline \multicolumn{7}{|c|}{ Root mean square (RMS) } & \multicolumn{2}{|c|}{3.96} & \multicolumn{2}{|c|}{0.43} & \multicolumn{2}{|c|}{0.07} \\
\hline \multicolumn{7}{|c|}{ Coefficient of determination $\left(\mathrm{R}^{2}\right)$} & \multicolumn{2}{|c|}{0.975} & \multicolumn{2}{|c|}{0.990} & \multicolumn{2}{|c|}{0.99} \\
\hline
\end{tabular}

a) Absolute error

b) Actual value

c) Predicted value

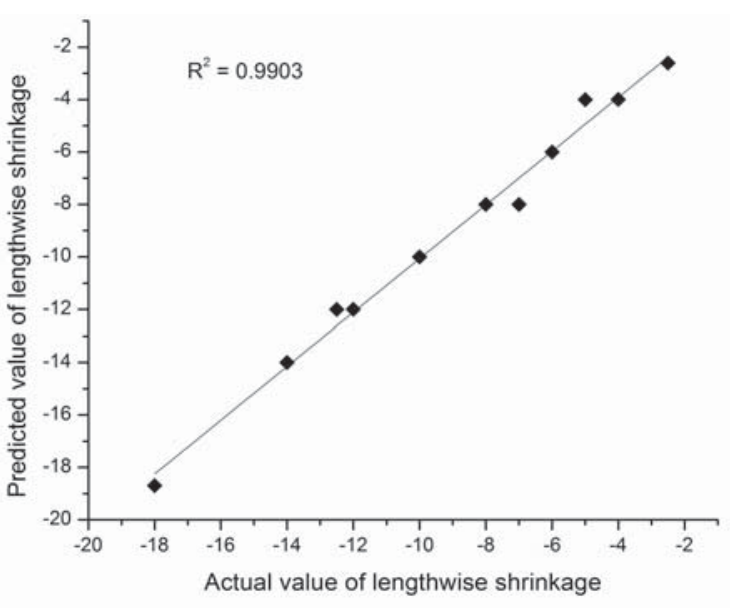

Figure 19: Correlation between actual and predicted values of lengthwise shrinkage of single jersey cotton knitted fabric

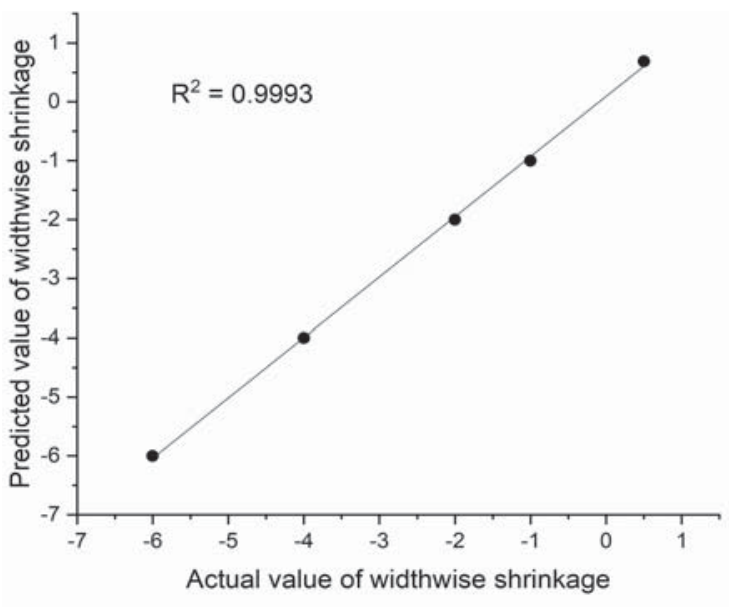

Figure 20: Correlation between actual and predicted values of widthwise shrinkage of single jersey cotton knitted fabric 


\section{Conclusion}

Single jersey cotton knitted fabrics have the tendency to change their dimension permanently according to the variables in knitted fabric manufacturing and processing. From the prepared model, it will be possible to predict the dimension of the fabric before its production in industrial scale if the variables and their effects are known and controlled. From the empirical study, it has been elucidated that in addition to yarn count and stitch length, the overfeed percentage of a stenter machine also has a great impact on the fabric mass per unit area and shrinkage property of a single jersey knitted fabric. By increasing overfeed percentage in a stenter machine, the lengthwise shrinkage property of a single jersey fabric can also be improved for all yarn's count and stitch length considered in this work; however, this also increases the mass per unit area of the fabric. On the other hand, knitted fabric made from yarns with higher count with a lower range of stitch length exhibited better performance in both length- and widthwise shrinkage property. Again, the developed fuzzy intelligent model confers an outstanding clarification about the interaction between the variables and their effect on the mass per unit area and shrinkage property of a plain single jersey knitted fabric. This model may act as a decision-making tool and support the textile engineer to prognosticate knitted fabric mass per unit area, and lengthand widthwise shrinkage in advance, which can minimize production time, costs and wastages generated in developing and improving the quality of the knitted fabric. In the future of this ongoing research, we will consider input variables from a compactor machine for the prediction of finished fabric properties, which will further extend the applicability of this model.

\section{Acknowledgements}

The authors offer their sincerest gratitude to Adurey knit Composite, Thermax group Ltd, especially for giving the opportunity to prepare all samples as well as for providing the scopes in a laboratory to perform the tests in this research work.

\section{References}

1. HEAP, S. Allan, STEVENS, Jill C. Shrinkage: If you can predict it then you can control it. Cotton Technology International, September:1-7, 1992. Available on World Wide Web: <http:// cottontech.co.uk/index_htm_files/ShrinkagePredictionPro.pdf $>$.

2. HURD, J. C. H., DOYLE, P. J. Fundamental aspects of the design of knitted fabrics. Journal of the Textile Institute (Proceedings), 1953, 44(8), 561-78, doi: 10.1080/19447015308687861.

3. MUNDEN, D. L. The geometry and dimensional properties of plain-knit fabrics. Journal of the Textile Institute, 1959, 50(7), 37-41, doi: 10. 1080/19447025908659923.

4. BLACK, David H. Shrinkage control for cotton and cotton blend knitted fabrics. Textile Research Journal, 1974, 44(8), 606-611, doi: 10. 1177/ 004051757404400810.

5. HSU, Li Hua, and CHEEK, Lenore. Dimensional stability of ramie, cotton and rayon knit fabrics. Clothing and Textiles Research Journal, 1989, 7(2), 32-36, doi: 10.1177\%2F0887302X8900700205.

6. SHARMA, I. C., GHOSH, S., GUPTA, N. K. Dimensional and physical characteristics of single jersey fabrics. Textile Research Journal, 1985, 55(3), 149-56, doi: 10.1177\%2F004051758505500303.

7. MARMARALI, A. Bayazit. Dimensional and physical properties of cotton/spandex single jersey fabric. Textile Research Journal, 2003, 73(1), 11-14, doi: 10.1177/004051750307300102.

8. KANE, C. D., PATIL, U. J., SUDHAKAR, P. Studies on the influence of knit structure and stitch length on ring and compact yarn single jersey fabric properties. Textile Research Journal, 2007, 77(8), 572-582, doi: 10.1177\%2F0040517507078023.

9. KNAPTON, J. J. F., AHRENS, F. J., INGENTHRON, W. W., FONG, W. The dimensional properties of knitted wool fabrics part ii: $1 \times 1,2 \times 2$ rib, and half cardigan structures. Textile Research Journal, 1968, 38(10), 1013-1026, doi: $10.1177 / 004051756803801005$.

10. KNAPTON, J. J. F., RICHARDS, S., FONG, W. The dimensional properties of knitted wool fabrics. Part III: The plain-knit structure in machine-washing and tumble-drying. Textile Research Journal, 1970, 40(6), 543-553.

11. FLETCHER, Hazel M., ROBERTS, S. Helen. Dimensional stability and elastic properties of 
plain knit wool fabrics with and without Wurlan finish. Textile Research Journal, 1965, 35(11), 993-999, doi: 10.1177\%2F004051756503501105.

12. SHINN, W. E. An engineering approach to jersey fabric construction. Textile Research Journal, 1955, 25(3), 270-277, doi: 10.1177/ 004051755502500314.

13. BOGDAN, J. F. The prediction of cotton yarn strengths. Textile Research Journal, 1967, 37(6), 536-537, doi: 10.1177/004051756703700617.

14. HEAP, S. Allan, GREENWOOD, Peter F., LEAH, Robert D., EATON, James T., STEVENS, Jill. C., KEHER, Pauline. Prediction of finished weight and shrinkage of cotton knits- the starfish project. Part I: Introduction and general overview. Textile Research Journal, 1983, 53(2), 109-119, doi: 10.1177/004051758305300208.

15. HEAP, S. Allan., GREENWOOD, Peter F., LEAH, Robert D., EATON, James T., STEVENS, Jill C., KEHER, Pauline. Prediction of finished relaxed dimensions of cotton knits- the starfish project: Part II: Shrinkage and the reference state. Textile Research Journal, 1985, 53(2), 21122, doi: 10.1177/004051758305300208.

16. MAVRUZ, Serin, OGULATA, R. Tugrul. Taguchi approach for the optimisation of the bursting strength of knitted fabrics. Fibres and Textiles in Eastern Europe, 2010, 79(2), 78-83.

17. ULSON de SOUZA, Antônio Augusto, CABRAL CHEREM, Luiz Felipe, GUELLI U SOUZA, Selene M. A. Prediction of dimensional changes in circular knitted cotton fabrics. Textile Research Journal, 2010, 80(3), 236-52, doi: 10.1177/0040517509105598.

18. RAY, Sadhan, Chandra. An insight to the modeling of $1 \times 1$ rib loop formation process on circular weft knitting machine using computer. Journal of The Institution of Engineers (India): Series E, 2015, 96(2), 99-106, doi: 10.1007/ s40034-015-0061-5.

19. BRENNER, F. C., SCOCCA, P. M. The prediction of the micronaire value for a bale or a group of bales - A statistical study. Textile Research Journal, 1956, 26(11), 899-902, doi: 10.1177/ 004051755602601109.

20. UNAL, Pelin Gurkan., ÜREYEN, Mustafa Erdem, MECIT, Diren. Predicting properties of single jersey fabrics using regression and artificial neural network models. Fibers and Polymers, 2012, 13(1), 87-95, doi: 10.1007/s12221-012-0087-y.
21. JAMSHAID, Hafsa, HUSSAIN, Tanveer, ZULFIQAR, Ali Malik. Comparison of regression and adaptive neuro-fuzzy models for predicting the bursting strength of plain knitted fabrics. Fibers and Polymers, 2013, 14(7), 1203-1207, doi: 10.1007/s12221-013-1203-3.

22. MAJUMDAR, Abhijit, GHOSH, Anindya. Yarn strength modelling using fuzzy expert system. Journal of Engineered Fibers and Fabrics, 2008, 3(4), 61-68, doi: 10.1177/155892500800300408.

23. HOSSAIN, Ismail, HOSSAIN, Altab, CHOUDHURY, Imtiaz Ahmed, MAMUN, Abdullah Al. Fuzzy knowledge based expert system for prediction of color strength of cotton knitted fabrics. Journal of Engineered Fibers and Fabrics, 2016, 11(3), 33-44, doi: 10.1177\%2F 155892501601100306.

24. HAQUE, Abu Naser Md Ahsanul., SMRITI, Shamima Akter, HUSSAIN, Manwar, FARZANA, Nawshin, SIDDIQA, Fahmida, ISLAM, Md Azharul. Prediction of whiteness index of cotton using bleaching process variables by fuzzy inference system. Fashion and Textiles, 2018, 5(4), 1-13, doi: 10.1186/s40691-017-0118-9.

25. HAQUE, Abu Naser Md Ahsanul, SMRITI, Shamima Akter, FARZANA, Nawshin, SIDDIQA, Fahmida, ISLAM, Md Azharul. Fuzzy modeling for prediction of bursting strength of cotton knitted fabric using bleaching process variables. AATCC Journal of Research, 2019, 6(1), 29-37, doi: 10.14504/ajr.6.1.5.

26. WONG, A. S. W., Li, Y., YEUNG, P. K. W. Predicting clothing sensory comfort with artificial intelligence hybrid models. Textile Research Journal, 2004, 74(1), 13-19, doi: 10.1177\%2 F004051750407400103.

27. ONAL, Levent, ZEYDAN, Mithat, KORKMAZ, Mahmut, MEERAN, Sheik. Predicting the seam strength of notched webbings for parachute assemblies using the Taguchi's design of experiment and artificial neural networks. Textile Research Journal, 2009, 79(5), 468-478, doi: 10. 1177\%2F0040517508099921.

28. BEHERA, B. K., GOYAL, Y. Artificial neural network system for the design of airbag fabrics. Journal of Industrial Textiles, 2009, 39(1), 45-55, doi: $10.1177 / 1528083708093335$.

29. GUO, Z., WONG, W., LEUNG, S., LI, M. Applications of artificial intelligence in the apparel industry: A review. Textile Research 
Journal, 2011, 81(18), 1871-92, doi: 10.1177/ 0040517511411968.

30. RAHMAN, Mokhlesur, HABIB, Tarek. A preprocessed counterpropagation neural network classifier for automated textile defect classification. Journal of Industrial and Intelligent Information, 2016, 4(3), 209-17, doi: 10.18178/jiii.4.3.209-217.

31. HOSSAIN, Ismail, CHOUDHURY, Imtiaz Ahmed, MAMAT, Azuddin Bin, SHAHID, Abdus, KHAN, Ayub Nabi, HOSSAIN, Altab. Predicting the mechanical properties of viscose/ Lycra knitted fabrics using fuzzy technique. $A d$ vances in Fuzzy Systems, 2016, 2016, 1-9, doi: $10.1155 / 2016 / 3632895$.

32. HOSSAIN, Ismail, HOSSAIN, Altab, CHOUDHURY, Imtiaz Ahmed. Color strength modeling of viscose/Lycra blended fabrics using a fuzzy logic approach. Journal of Engineered Fibers and Fabrics, 2015, 10(1), 158-68, doi: 10.1155/2016/3632895.

33. VADOOD, Morteza. Predicting the color index of acrylic fiber using fuzzy-genetic approach. The Journal of The Textile Institute, 2014, 105(7), 779-788, doi: 10.1080/00405000.2013.849844.

34. AATCC Test Method 135-2004. Dimensional changes of fabric after home laundering. American Association of Textile Chemists and Colorist.

35. ISO 3801:1977 Textiles-Woven fabrics-Determination of mass per unit length and mass per unit area, pp. 1-4.

36. HERVA, Marta, FRANCO-URÍA, Amaya, CARRASCO, Eugenio F., ROCA, Enrique. Application of fuzzy logic for the integration of environmental criteria in ecodesign. Expert Systems with Applications, 2012, 39(4), 4427-4431, doi: 10.1016/j.eswa.2011.09.148.

37. DARAIN, Kh Mahfuz Ud, JUMAAT, Mohd Zamin, HOSSAIN, Md Altab, HOSEN, Md
Akter, OBAYDULlAH, M., HUDA, Md Nazmul, HOSSAIN, I. Automated serviceability prediction of NSM strengthened structure using a fuzzy logic expert system. Expert Systems with Applications, 2015, 42(1), 376-389, doi: 10.1016/ j.eswa.2014.07.058.

38. ÇARMAN, Kazım. Prediction of soil compaction under pneumatic tires a using fuzzy logic approach. Journal of Terramechanics, 2008, 45(4), 103-108, doi: 10.1016/j.jterra.2008.10.001.

39. HOSSAIN, Ismail, CHOUDHURY, Imtiaz Ahmed, MAMAT, Azuddin Bin. Predicting the colour properties of viscose knitted fabrics using soft computing approaches. The Journal of The Textile Institute, 2017, 108(10), 1689-1699, doi: 10.1080/00405000.2017.1279004.

40. REPON, Md Reazuddin, SHIDDIQUE, Md Nura Alam, PAUL, Debasree, MAMUN, Rajib $\mathrm{Al}$, SHAHRIA, Sumaiya, QUAYUM, Mohaiminul. Effect of yarn count \& stitch length on the fabric width, GSM, WPI and CPI of $1 \times 1$ rib fabrics. International Journal of Textile Science, 2018, 7(4), 94-100, doi: 10.5923/j. textile.20180704.03.

41. IQBAL, Md Shaheen, MAMUN, Md Abdullah Al, SIDDIQUEE, Md Abu Bakar, ASIF, A. K. M. Ayatullah Hosne. Effect of finishing machine parameters on dimensional stability of single Lacoste cotton knitted fabric. Advances in Materials, 2016, 5(5), 35-43, doi: 10.11648/j.am. 20160505.12.

42. SAYED, Zubair Bin, ISLAM, Tarikul, CHAWDHURY, Nazif Hasan, AHMED, Mafzal. Effect of knitted structures and yarn count on the properties of weft knitted fabrics. Journal Textile Science and Technology, 2018, 4(2), 67-77, doi: 10. 4236/jtst.2018.42004. 